\title{
Permanent External Biliary Catheter: A Difficult Problem Managed by Rescue Technique of Hepatico- cholecysto-gastrostomy
}

\author{
Vikas Singla ${ }^{1}$ Ajit Kumar Yadav ${ }^{2}$ Anil Arora ${ }^{1}$ Arun Gupta² \\ ${ }^{1}$ Institute of Liver, Gastroenterology and Pancreaticobiliary \\ Sciences, Sir Ganga Ram Hospital, New Delhi, India \\ 2Department of Intervention Radiology, Sir Ganga Ram Hospital, \\ New Delhi, India \\ Address for correspondence Vikas Singla, DM, Institute of Liver, \\ Gastroenterology and Pancreaticobiliary Sciences, \\ Sir Ganga Ram Hospital, Rajinder Nagar 110060, New Delhi, \\ India (e-mail: singlavikas1979@gmail.com).
}

J Digest Endosc 2021;12:54-55.

\author{
Abstract \\ Keywords \\ - cholecystogastrostomy \\ - endoscopic ultrasound \\ - permanent external \\ biliary catheter
}

Percutaneous biliary drainage is commonly performed procedure after failure of ERCP in patients with biliary obstruction. Failure to internalization can lead to permanent external catheter. In the present case, problem of external biliary catheter was solved with hepaticocholecystogastrostomy. Guidewire from the external drain site could not be passed across the stricture, instead it was entering in the gall bladder. This was used as an opportunity to internalize the catheter. First EUS guided cholecystogastrostomy was performed, followed by placement of stent between right biliary system and the stomach, through the cholecystogastrostomy stent. This led to drainage of right biliary system into the stomach, and the external catheter could be removed. (c) 2020. Society of Gastrointestinal Endoscopy of India. This is an open access article published by Thieme under the terms of the Creative Commons Attribution-NonDerivative-NonCommercialLicense, permitting copying and reproduction so long as the original work is given appropriate credit. Contents may not be used for commercial purposes, or adapted, remixed, transformed or built upon. (https://creativecommons.org/licenses/by-ncnd/4.0/)External biliary drainage, a salvage procedure after failure of endoscopic retrograde cholangiopancreatography (ERCP), is associated with risk of permanent external biliary catheter. Permanent external biliary catheter is a troublesome situation and leads to deterioration in quality of life. A 70-year-old male presented with pruritus and jaundice. Imaging was suggestive of obstruction due to mass lesion at liver hilum, suggesting diagnosis of cholangiocarcinoma. During ERCP, wire could not be negotiated across the stricture; hence, rescue percutaneous transluminal biliary drainage (PTBD) was done. PTBD catheter could not be internalized because of non-negotiable stricture. As the guidewire from the PTBD site was repeatedly entering the gall bladder, hepaticocholecystogastrostomy was performed to internalize the PTBD catheter. PTBD catheter was first passed into collapsed gall bladder lumen, followed by saline infusion, leading to adequate distension of gall bladder ( $\mathbf{- F i g}$. 1a). Endoscopic ultrasound (EUS)-guided cholecystogastrostomy was done using $15 \mathrm{~mm} \times 10 \mathrm{~mm}$ lumen-apposing stent (Hot axios, Boston scientific, Marlborough, USA) (- Fig. 1b); through the metal stent, $10 \mathrm{Fr}, 5 \mathrm{~cm}$ double pigtail plastic stent (C-Flex, Boston Scientific, Spencer, USA) was placed. Next day, from the PTBD site, guidewire was negotiated from right hepatic duct (RHD), across the gall bladder, through the cholecystogastrostomy stent into the gastric lumen ( - Fig. 2a), followed by self-expandable metallic stent (SEMS) placement (10 mm, $8 \mathrm{~cm}$, Boston Scientific, Natick, MA, USA) ( $\mathbf{- F i g . ~ 2 b ) ~ t h r o u g h ~ t h e ~ t r a n s h e p a t i c ~ r o u t e , ~ c o n n e c t i n g ~ R H D ~}$ to gastric lumen. PTBD catheter was removed next day, and further clinical course was uneventful. Failure to internalize published online May 11, 2020
DOI https://doi.org/

$10.1055 / \mathrm{s}-0040-1718861$

ISSN 0976-5042.
(C)2020. Society of Gastrointestinal Endoscopy of India.

This is an open access article published by Thieme under the terms of the Creative Commons Attribution-NonDerivative-NonCommercial-License, permitting copying and reproduction so long as the original work is given appropriate credit. Contents may not be used for commercial purposes, or adapted, remixed, transformed or built upon. (https://creativecommons.org/licenses/by-nc-nd/4.0/).

Thieme Medical and Scientific Publishers Pvt. Ltd. A-12, 2nd Floor, Sector 2, Noida-201301 UP, India 

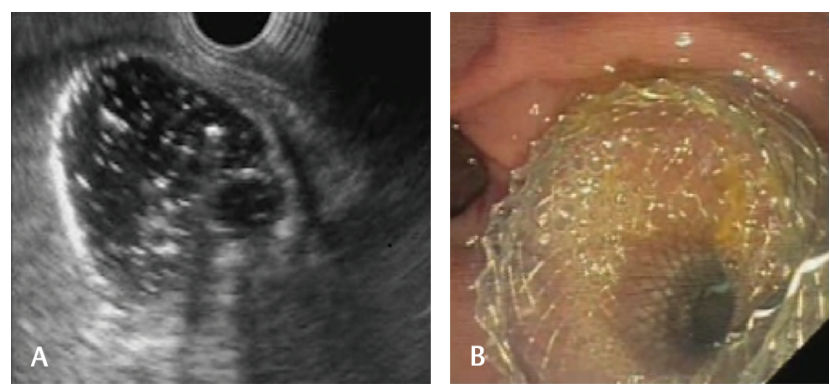

Fig. 1 (a) Transgastric endoscopic ultrasound showing distended gall bladder; fluid was injected through percutaneous transluminal biliary drainage (PTBD) catheter to distend the gall bladder. (b) Cholecystogastrostomy; metal stent placed between gall bladder and gastric antrum.
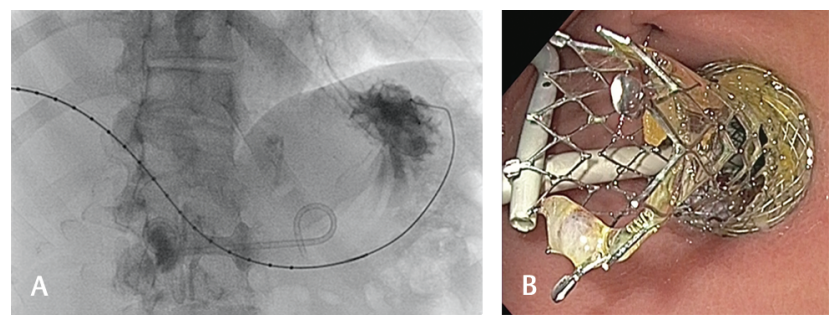

Fig. 2 (a) Guidewire placed across the PTBD site through the gall bladder in gastric lumen. Double pigtail stent across the cholecystogastrostomy metal stent can also be seen. (b) Biliary self-expandable metallic stent (SEMS) placed through the percutaneous transluminal biliary drainage (PTBD) site. Internal end of the stent can be seen in the gastric lumen; biliary stent is surrounded by cholecystogastrostomy stent. Wider stent is cholecystogastrostomy site, lumen-apposing stent.

the catheter is a common problem with PTBD. ${ }^{1,2}$ Various techniques $^{3}$ have been used to internalize the external catheter. Law et $\mathrm{al}^{3}$ reported a case where EUS-guided hepaticogastrostomy was performed to internalize the leftsided PTBD catheter. In the present case, PTBD was done on right biliary system; hence, EUS guided hepaticogastrostomy was not possible. As the guidewire from the PTBD site

\begin{tabular}{|l|l|}
\hline Vikas Singla & Writing the manuscript \\
\hline $\begin{array}{l}\text { Ajit Kumar } \\
\text { Yadav }\end{array}$ & $\begin{array}{l}\text { Collection of all the images and writing of } \\
\text { manuscript }\end{array}$ \\
\hline Anil Arora & Designing the work and writing the manuscript \\
\hline Arun Gupta & Revision of manuscript \\
\hline
\end{tabular}

was entering in gall bladder lumen, this was used as an opportunity to internalize the external biliary catheter.

\section{Authors Contribution}

\section{Conflicts of Interest}

None declared.

\section{References}

1 Laméris JS, Stoker J, Nijs HG, et al. Malignant biliary obstruction: percutaneous use of self-expandable stents. Radiology 1991;179(3):703-707

2 Piñol V, Castells A, Bordas JM, et al. Percutaneous self-expanding metal stents versus endoscopic polyethylene endoprostheses for treating malignant biliary obstruction: randomized clinical trial. Radiology 2002;225(1):27-34

3 Law R, Sanchez-Ocana Hernandez R, de la Serna-Higuera C, Perez-Miranda M. EUS-guided biliary drainage for internalization of percutaneous transhepatic biliary drainage. VideoGIE 2017;2(11):301-302 